\title{
РАЗВИТИЕ КОММУНИКАТИВНОЙ КОМПЕТЕНЦИИ В ПРОЦЕССЕ ОБУЧЕНИЯ ИНОСТРАННОМУ ЯЗЫКУ В НЕЯЗЫКОВОМ ВУЗЕ В УСЛОВИЯХ ДИСТАНЦИОННОГО ОБРАЗОВАНИЯ
}

\section{COMMUNICATIVE COMPETENCE WHILE TEACHING FOREGN LANGUAGE LEARNING IN A NON-LANGUAGE UNIVERSITY UNDER THE CONDITIONS OF DISTANCE EDUCATION}

\section{K. Malysheva} M. Ryabinina

Summary: The purpose of the article is to to review and systematize modern techniques of distance education in the aspect of their use for the formation of communicative competence in students of non-linguistic universities. Method of systematization and generalization, method of description, comparative method have been used. Electronic technologies that can be used as a means of teaching foreign languages were analyzed. It has been established that modern information technologies introduced into the educational process contribute to a more effective perception of educational information.

Keywords: communicative competence, students of non-linguistic universities, distance education, information and educational technologies, Edmodo, Moodle, Blackboard.

\author{
Малышева Ксения Михайловна \\ старший преподаватель, Тихоокеанский \\ государственный университет, г. Хабаровск \\ kseniammalysheva@gmail.com \\ Рябинина Мария Васильевна \\ старший преподаватель, Тихоокеанский \\ государственный университет, г. Хабаровск
}

004673@pnu.edu.ru

Аннотация: Целью статьи является обзор и систематизация современных средств дистанционного образования в аспекте их использования для формирования коммуникативной компетенции у обучающихся неязыковых ВУЗов. Метод систематизации и обобщения, метод описания, сравнительный метод. Были проанализированы электронные технологии, которые могут быть использованы как средство обучения иностранным языкам. Установлено, что современные информационные технологии, внедряемые в образовательный процесс, способствуют более эффективному восприятию учебной информации.

Ключевые слова: коммуникативная компетенция, студенты неязыковых ВуЗов, дистанционное образование, информационно-образовательные технологии, Edmodo, Moodle, Blackboard.

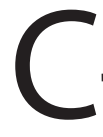
истема высшего образования во все времена должна отвечать актуальным общественным запросам и организовывать учебный процесс, исходя из текущих реалий и возможностей. Современный этап развития мирового общества характеризуется всеобщей цифровизацией и ориентацией на максимально оптимизированный образовательный процесс. Ход развития событий диктует свои условия, существенным фактором, повлиявшим на образовательный процессе стала пандемия короновируса 2019-2020 гг., которая обусловила всеобщий переход на дистанционный формат обучения и, как следствие, вынужденное использование дистанционных образовательных Современные условия требует от системы образования усовершенствованных подходов к подготовке выпускников неязыковых ВУЗов во всех сферах жизнедеятельности. Использование в образовании, в том числе в иноязычном, электронных технологий и источников информации в настоящее время, в условиях вынужденной необходимости организации дистанционного формата образования, набирает популярность, так как позволяет формировать регулятивные и аналитические умения, навыки работы в информационном пространстве, а также способствует формиро- ванию коммуникативной компетенции и оптимизации учебного времени. Мультимедийные технологии, используемые на уроке иностранного языка, способствуют поддержанию высокого уровня мотивации, оптимальной презентации и отработке учебных материалов и его закрепления с целю дальнейшего использования в учебной или другой деятельности. Такое положение создало необходимость разработки модели, сочетающей в себе использование электронных образовательных ресурсов и традиционных форм обучения, и учитывающей индивидуальные особенности обучающихся, т.е. ориентированной на индивидуализацию в процессе обучения.

Современное российское образование характеризуется инновационным подходом в изменяющимся условиям на всех уровнях - социальном, экономическом, политическом. В 2019-2020 гг. перед Министерством образования РФ встала непростая задача по реализации эффективного образовательного процесса в условиях пандемии коронавируса, когда все обучающие были переведены на дистанционный формат обучения. Как показала практика за этот период качество образования осталось на должном уровне, об этом свидетельствуют 
данные, размещенные на сайте Министерства науки и высшего образования Российской Федерации, согласно которым большинство участников образовательного процесса довольны организацией дистанционного обучения и его результатами. При таком положении дел применение программного обеспечения, позволяющего осуществлять дистанционное образование, становится перспективным и актуальным, в этой связи требуется детально изучить особенности его использования и разработать методику его эффективной работы.

В рамках данной статьи сосредоточим внимание на занятиях по иностранному языку в неязыковых ВУЗах, организованных дистанционно при помощи информационно-технических средств. Придерживаясь стандартов ФГОС в плане иноязычного образования, образовательное учреждение должно обеспечить эффективное формирование коммуникативной компетенции у обучающихся, что и является главной целью курса иностранного языка в неязыковом ВУЗе. Эффективном вспомогательным учебным средством становится электронные образовательные ресурсы.

По убеждению методистов, применение разнообразных электронных технологий и источников информации (текст, аудио, видео, изображения), а также заданий различных типов способствуют учету индивидуальных особенностей обучающихся и реализации принципа индивидуализации в процессе обучения, что на современном этапе развития общества, является приоритетной образовательной задачей [2]. Такие исследователи, как Д.Д. Климентьев [1], И.В. Столярова [5] и др. убеждены в том, что в вынужденных условиях дистанционного и смешанного обучения эффективное использование электронных образовательных ресурсов способно помочь достичь высоких показателей в образовательном процессе. Обучающиеся могут работать максимально эффективно для себя, следовательно, качество обучения повышается. Исходя из этого представляется целесообразным разработать программы по развитию навыков на изучаемом иностранном языке с помощью электронных технологий как средства обучения иностранным языкам.

Дистанционное обучение, осуществляемое при помощи электронных образовательных средств, обладает своей спецификой, которую нужно учитывать при разработке программы обучения. В случае использования данных технологий в неязыковом ВУЗе важным моментом является соблюдение санитарно-эпидемиологических правил СанПиН 2.4.2.1178-02, согласно которым, необходимо учитывать ограничения по времени, отводимому на домашнее задание и использование медиасредств и технических средств обучения (ТСО) [5]. Поэтому при организации уроков в формате дистанционного или смешанного обучения либо с использованием элек- тронно-компьютерных технологий, необходимо учитывать данные требования.

Чаще всего преподавателям самим приходится подбирать материалы для таких занятий, сочетающих в себе использование образовательных электронных технологий и традиционных методов обучения. На сегодняшний день существуют разнообразные ресурсы для отработки различных речевых умения и навыков, что, в конечном итоге, ведет к формированию коммуникативной компетенции. Современные информационные технологии позволяют сделать образовательный процесс более динамичным и интерактивным, создавать коммуникативные задачи, которые максимально приближены в реальному, «живому» общению. Использование такого рода ситуативных задач является неотъемлемым условием для успешного развития коммуникативной компетенции. С каждым годом создается все больше программного обеспечения для использования в образовании. Все эти инструменты позволяют не только оптимизировать время учителя на уроке, но и частично автоматизировать проверку работ и подготовку материалов к занятиям по иностранному языку в неязыковом ВУЗе.

В связи с тем, что дистанционное и смешанное обучение предполагает сочетание аудиторной работы учителя и применения информационных технологий для организации онлайн-обучения как на уроке, так и вне его, учителю необходимо иметь широкий спектр инструментов для наиболее эффективной реализации такой формы обучения. Основными инструментами для этих целей будут являться система дистанционного обучения (СДО) и систем управления обучением или различные редакторы учебного контента.

Разрабатывая программу по развитию навыков на изучаемом иностранном языке с помощью электронных технологий как средства обучения иностранным языкам представляется целесообразным дать характеристику существующим на сегодняшний день вариантом программного обеспечения (ПО), на основе которого строится программа. Наиболее распространенными являются, например, Moodle, Canvas, Claroline, ATutor, Blackboard, Edmodo.

Портал Capterra приводит рейтинг наиболее популярного программного обеспечения для систем управления обучением. Рейтинг составлен по 3 основным параметрам: популярность, доступность и удобство интерфейса для пользователя.

Самыми популярными сервисами являются Edmodo (350 тысяч клиентов, более 58 млн. пользователей), Moodle (около 80 тысяч клиентов, около 90 миллионов пользователей) и Blackboard (20 тысяч клиентов и 20 миллионов пользователей). Кроме количества пользо- 
вателей в данном рейтинге учитывались ссылки на них в социальных сетях Facebook, Tweeter и LinkedIn.

Рейтинг, основанный на критерии "доступность", подразумевает учет стоимости, функциональности, ценности и общего качества программного обеспечения. Здесь лидирующие позиции занимают TalentLMS, Accord LMS и SkyPrep. Moodle занимает 7 место, других лидеров по популярности в этом рейтинге нет.

В рейтинге по критерию удобства интерфейса первые позиции занимают SkyPrep, Bridge и Litmos LMS. Этот рейтинг формировался по следующим параметрам: простота использования, сервис клиента. При этом большинство сервисов в этом рейтинге направлены на корпоративное обучение, возможности академического образования в приведенных сервисах реализованы в меньшей степени.

В российском образовании наибольшей популярностью пользуются такие системы ДО как Moodle, Canvas, Edmodo и Прометей.

В дополнение к перечисленным критериям, можно составить более подробный список характеристик для сравнения систем ДО [4]. Онлайн-платформа Edmodo выделяется среди других LMS тем, что изначально создавалась именно как своеобразная образовательно-социальная сеть для учителей, обучающихся и их родителей. Edmodo обладает достаточно приятным интерфейсом с множеством интерактивных сервисов и широкими возможностями использования сторонних приложений типа Dropbox, Google Drive и Microsoft Office 365

Edmodo играет важную роль в системе управления обучением. Платформа Edmodo заняла свою нишу в начальном образовании, и вместо того, чтобы предлагать инструменты для создания автономных онлайн-курсов, ее электронные функции дополняют традиционные учебные занятия и способствуют развитию смешанных форм обучения.

Студенты, преподаватели и родители могут бесплатно создавать аккаунты, хотя у Edmodo есть и премиум-наборы для аналитики, приоритетного обучения, поддержки и синхронизации. Квоты варьируются в зависимости от округа, студенческий аккаунт стоит 1 \$а год пользования.

Что касается осуществления работы, то преподаватели могут использовать ленту Stream для того, чтобы размещать домашние задания, вместе с описаниями, датами и приложениями, рекомендовать исправить ответы и менять объем задания

У обучающихся есть возможность оставлять ответы, прикреплять посты и добавлять замечания. Кроме того, в Edmodo имеется функция викторины, которую можно сохранить и загрузить из библиотеки («Коллекции») преподавателя, либо придумать на ходу. Как альтернативный вариант, преподаватель может отослать один вопрос студенту или группе, используя опрос. Такие ситуативные задачи имитируют ситуации реального общения и являются необходимым компонентом для формирования коммуникативной компетенции студентов неязыковых ВУЗов.

Для получения обратной связи преподаватели могут использовать функцию Snapshot. Проведя опрос преподаватели могут получить исчерпывающую и актуальную информацию об успехах обучающихся. Все, что требуется от учителя - это выбрать группу и учебный стандарт. После того, как студенты ответили на вопросы, можно увидеть, кто из обучающихся знает программу, а кому следует дополнительно позаниматься. Такой формат диалога позволит сократить время на обратную связь и предоставит преподавателю данные в систематизированном виде, что, безусловно, поможет оптимизировать образовательный процесс.

Edmodo автоматически перенаправляет Snapshot тем обучающимся, которые не сдали тест, также даются рекомендации относительно того, какие источники может использовать обучающийся [7].

Резюмируя вышесказанное, можно сказать, что образовательная платформа Edmodo на одну треть является системой управления образованием, а на две трети - педагогической социальной сетью, в которой взаимодействуют учителя, обучающиеся и родители. Она обладает всеми характеристиками и сервисами, чтобы сделать образовательный процесс увлекательным и интересным.

Основываясь на большом опыте апробации смешанного обучения в разных странах и на разных ступенях обучения, на сегодняшний день можно найти множество рекомендаций по реализации того или иного варианта смешанного обучения. Но важно помнить, что в России существуют определенные требования к организации учебного процесса и учет которых является неотъемлемой частью образовательного процесса в современной школе [3].

Данные требования значительно ограничивают возможности преподавателя при разработке уроков. Тем не менее, существует множество инструментов, которые можно использовать при проведении уроков в формате смешанного обучения, что подразумевает использование электронных технологий как средства обучения иностранным языкам. При смешанном обучении учитель может ставить перед обучающимися на различных этапах урока задачи с использованием инструментов ин- 
формационной среды.

Использование инструментов образовательных электронных технологий и информационно-образовательной среды позволяет реализовать системно-деятельностный и индивидуальный подходы к обучению, повысить мотивацию учеников, а также эффективность учебного процесса в целом.

Иностранный язык является многоплановым предметом, включающим в себя обучение фонетике, лексике, грамматике, чтению, аудированию и письму. Помимо основных речевых и языковых умений на уроках иностранного языка также уделяется внимание домашнему чтению и страноведению, что является необходимым условием развития коммуникативной компетенции.

Таким образом, существует множество критериев, по которым образовательная организация или сам преподаватель, использующий технологию смешанного обучения, выбирают ту или иную программу и средства обучения. В результате сравнения наиболее популярных в России систем дистанционного обучения, было выявлено, что интегральная оценка функциональности системы выглядит следующим образом: Прометей - 81\%, Moodle $61 \%$, Canvas - 69\%, Edmodo - 67\%. Система Edmodo отвечает требованиям большинства преподавателей, так как она обладает более интересным интерфейсом, похожим на социальную сеть, и средством осуществления связи между преподавателем и обучающимися и их родителями. Подводя итог вышесказанному, можно резюмировать, что использование технологий электронного обучения в условиях дистанционного обучения в неязыковом Вузе в аспекте формирования у обучающихся коммуникативной компетенции, необходимо строить с учетом возрастных особенностей обучающихся, уровня и особенностей развития их интеллекта и психологических особенностей, чтобы применение этой технологии было максимально эффективным. Мультимедийные технологии, используемые на уроке иностранного языка, способствуют поддержанию высокого уровня мотивации, оптимальной презентации и отработке учебных материалов и его закрепления с целю дальнейшего использования в учебной или другой деятельности. Такое положение создало необходимость разработки модели, сочетающей в себе использование электронных образовательных ресурсов и традиционных форм обучения, и учитывающей индивидуальные особенности обучающихся, т.е. ориентированной на индивидуализацию в процессе обучения.

Использование дистанционного обучения на уроках иностранного языка существенно расширяет возможности учителя, позволяя оптимизировать его работу и организовать взаимодействие с учениками в новом и зачастую более эффективном режиме. Организация дистанционного обучения на разнообразных платформах, предназначенных для этого (Moodle, Edmodo) делает учебный процесс более интересным и соответствующим реалиям современности. Несмотря на все ограничения, современный учитель обладает большим количеством инструментов, которые можно использовать при проведении уроков в таком формате.

\section{ЛИТЕРАТУРА}

1. Климентьев Д.Д. Опыт обучения иностранным языкам в вузе в условиях дистанционного образования: анализ и перспективы // Актуальные проблемы современного иноязычного образования. - Курск: Курский государственный университет, 2020. - С. 6-14.

2. Министерство науки и высшего образования Российской Федерации URL: https://www.minobrnauki.gov.ru/ru/press-center/card/?id_4=2622, дата 06ращения 25.09.2020.

3. Санитарно-эпидемиологические правила СанПиН 2.4.2.1178-02 «Гигиенические требования к условиям обучения в общеобразовательных учреждениях URL: http://docs.cntd.ru/document/901835064, дата обращения 25.09.2020.

4. Сравнительная характеристика систем дистанционного обучения (СД0). URL: http://www.infotechno.ru/analizSD0.htm, дата 0бращения 25.09.2020.

5. Столярова И.В. Применение тестовых технологий в обучении иностранным языкам в условиях дистанционного образования // Современный взгляд на науку и образование. - М.: Издательство «Перо», 2020. - С. 97-101.

6. Теория множественного интеллекта Гарднера (ВВП). URL: http://www.psychologos.ru/articles/view/teoriya_mnozhestvennogo_intellekta_gardnera_vvp, дата обращения 25.09.2020.

7. Edmodo - в помощь учителям, ученикам и родителям. URL: http://ru.pcmag.com/edmodo-Ims/22660/review/edmodo-v-pomoshch-uchiteliam-uchenikami-roditeliam, дата обращения 25.09.2020.

(c) Малышева Ксения Михайловна (kseniammalysheva@gmail.com), Рябинина Мария Васильевна (004673@pnu.edu.ru). Журнал «Современная наука: актуальные проблемы теории и практики» 